\title{
Factors associated with the development of secondary cancers after radioiodine therapy in differentiated thyroid cancer: $A$ multicenter retrospective study
}

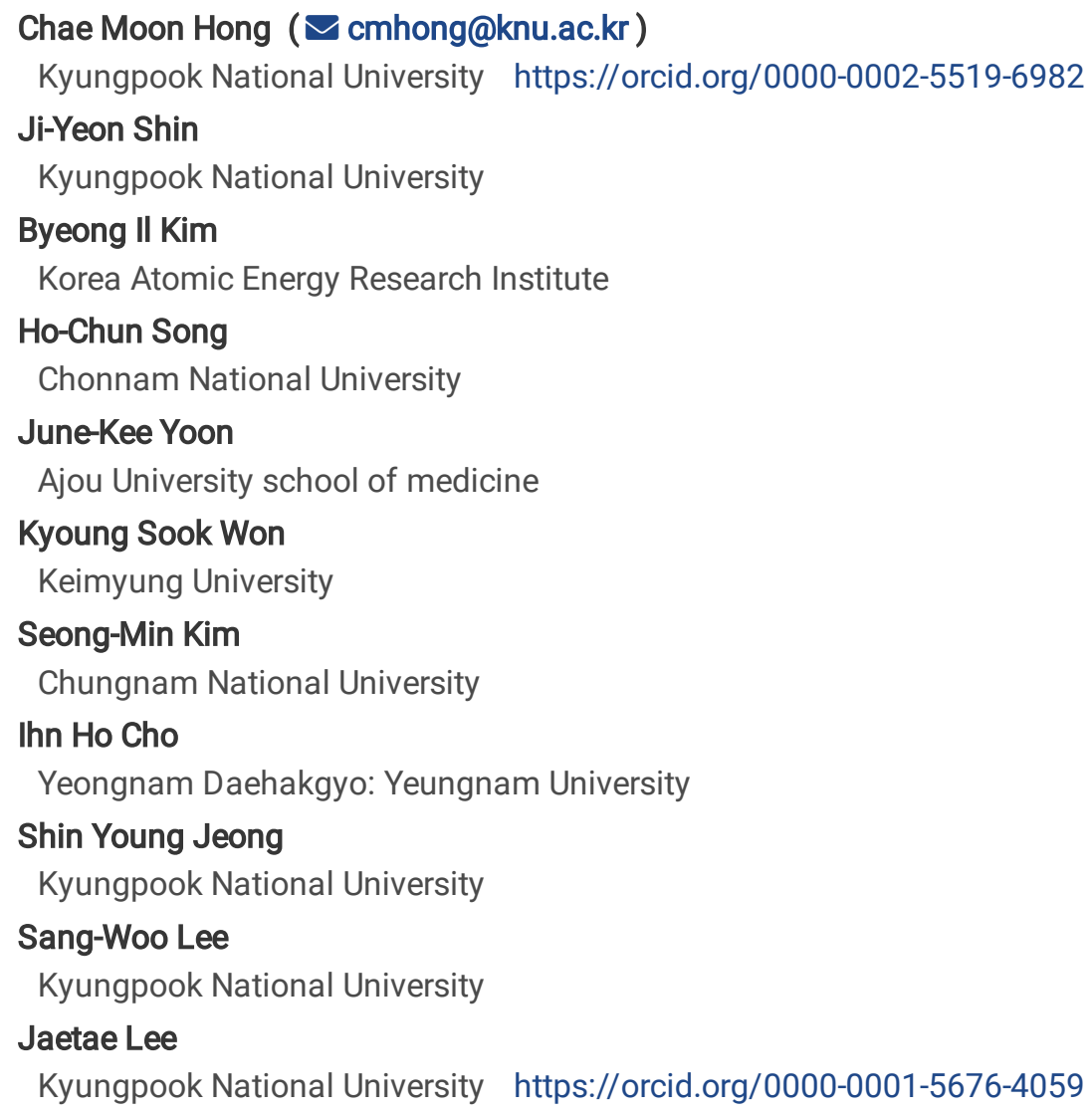

\section{Research Article}

Keywords: Thyroid cancer, Secondary caner, Radioiodine therapy, Radiation

Posted Date: August 17th, 2021

DOI: https://doi.org/10.21203/rs.3.rs-807505/v1

License: (c) (1) This work is licensed under a Creative Commons Attribution 4.0 International License. Read Full License 


\section{Abstract \\ Purpose}

The objective of this study was to estimate the incidence of secondary cancers and the factors associated with their development among patients who underwent radioiodine therapy (RIT) with differentiated thyroid cancer.

\section{Methods}

We retrospectively collected medical records for patients who underwent first RIT between January 1, 2000 and December 31, 2005 from seven tertiary hospitals in South Korea after total thyroidectomy for differentiated thyroid cancer. Cancer incidence and calculated standardized rate ratio was compared with Korean cancer incidence data. The association between the development of secondary cancers and various parameters was analyzed by Cox-proportional hazard regression.

\section{Results}

A total of 3106 patients were included in this study. Mean age at the time of diagnosis of thyroid cancer was $45.7 \pm 13.3$ years old, and 2669 (85.9\%) patients were female. The follow-up period was $11.9 \pm 4.6$ (range, 1.2-19.6) years. A total of 183 secondary cancers (5.6\%), which included 162 solid and 21 hematologic cancers occurred in 173 patients. There was no significant difference between solid cancer incidence in our study population who underwent RIT and the overall Korean population, but the incidence of hematologic cancers and total cancer in our study was significantly higher compared with that of the Korean population. A multivariate analysis identified independent prognostic factors for the development of secondary cancer including age at 1st RIT, male, and total cumulative dose over $200 \mathrm{mCi}$.

\section{Conclusion}

We need to assess the risk benefit for patients who receive over $200 \mathrm{mCi}$ of a total cumulative dose.

\section{Introduction}

The incidence of thyroid cancer has progressively increased worldwide [1, 2]. Following total thyroidectomy for differentiated thyroid cancer (DTC), radioiodine therapy (RIT) is widely used for remnant ablation, adjuvant treatment, or the treatment of persistent or recurrent disease [3]. Although radioiodine contributes to DTC treatment, the potential risk of developing secondary cancer after treatment has emerged as a concern because of the otherwise relatively good survival rates for DTC.

lonizing radiation and risk of cancer is well known from a large cohort of atomic bomb survivors [4, 5]. RIT for hyperthyroidism has recently been reported to be positively associated with cancer mortality [6], suggesting that the radiation hazard from radioiodine needs to be considered. However, the relationship between RIT and the development of secondary cancers in DTC patients after radioiodine treatment is complex $[7,8]$. A relatively low incidence of secondary cancers and many co-founding factors make it difficult to fully determine the risk. Sawka et al. reported a slightly increased relative risk (1.19) of secondary cancers after RIT in a meta-analysis in 2009 [7]. However, in their follow-up meta-analysis in 2018, there was no significant increase of secondary cancers following RIT [8]. Even in systematic reviews and meta-analyses, heterogeneous data (age-adjusted, age-unadjusted, missing cumulative dose) has affected the study quality to establish a relationship between RIT and secondary cancers [8].

With respect to leukemia, two nationwide, large cohort studies showed an increased incidence of leukemia after RIT [9, 10]. A metaanalysis also showed an increased relative risk (1.60) after RIT; however, multiple myeloma was decreased [8, 9]. In the case of secondary cancers, the results were much more complex. Secondary solid cancers appear to be increased after RIT in the SEER database, but they did not perform a detailed analysis that considered various clinical parameters $[9,11]$.

Because of the concerns of excess radiation exposure to patients, the dose of administered radioiodine has tended to be decreased, especially after the release of the 2015 ATA guidelines [12, 13]. For increasing the therapeutic efficacy and decreasing the side

Page $2 / 13$ 
effects, an optimized dose determination for radioiodine became important. Because large population-based studies did not include the clinical parameters of patients with DTC, they could not analyze the relationship between the occurrence of secondary cancers and the clinical parameters of the individual subjects.

Therefore, the objective of this study was to determine the incidence of secondary cancers and analyze the factors associated with the development of secondary cancer among patients who underwent RIT after surgery. We analyzed patient clinical characteristics in more detail including the initial and total cumulative dose of radioiodine as well as the clinical and pathologic status using the AJCC 8th staging system. These clinical parameters are helpful for providing evidence to perform clinical studies. Since F-18 FDG PET/CT has been used for the diagnosis of early cancer, we also determined whether the addition of screening with F-18 FDG imaging has had a beneficial diagnostic role on the early detection of secondary cancers during the first 5 years after surgery and RIT in DTC patients.

\section{Subjects And Methods \\ Patients and study design}

We retrospectively reviewed data for 3872 DTC patients who underwent first RIT between January 1, 2000 and December 31, 2005 after total thyroidectomy. We collected the data from seven tertiary hospitals in South Korea. The Institutional Review board approved this study and informed consent was waived.

Retrospective data were collected based on a meticulous chart review. We collected age, sex, type of thyroid cancer, date of surgery, risk stratification based on the revised 2015 American Thyroid Guidelines [12], date and dose of first radioiodine administration, total cumulative dose of radioiodine, development of secondary cancers, type of secondary cancer, and date of development of secondary cancer. Based on the retrospective surgery report, pathology report, and chart review, we re-classified patients using the AJCC (8th) staging system. Patients were categorized based on 23 cancer types, except thyroid cancer, according to cancer statistics in Korea and included [1]: Lip/oral cavity/pharynx (C00-C14), esophagus (C15), stomach (C16), colon/rectum (C18-C20), liver (C22), gallbladder/biliary (C23-C24), pancreas (C25), larynx (C32), lung (C33-C34), breast (C50), cervix uteri (C53), corpus uteri (C54), ovary (C56), prostate (C61), testis (C62), kidney (C64), bladder (C67), bran/CNS (C70-C72), Hodgkin's lymphoma (C81), nonHodgkin's lymphoma (C82-C86, C96), multiple myeloma (C90), leukemia (C91-C95), and other/ill-defined cancer.

The patients with follow-up periods less than 2 years or insufficient data lacking clinicopathologic parameters were excluded from the analysis $(n=645)$. To prevent the concordant development of solid cancer, we excluded the patients who were diagnosed with a solid cancer within 2 years after RIT $(n=24)$. As secondary hematologic cancers appearing earlier increased in incidence after radiation therapy [14], we included all patients who developed a hematologic cancer. The patients who were diagnosed as "other cancer" before the diagnosis of thyroid cancer $(n=45)$ and who underwent external radiotherapy during the follow-up period $(n=52)$, were excluded from the analysis (Fig. 1).

Patients were prepared with thyroid hormone withdrawal and a low iodine diet and the administered radioactivity was determined empirically $[15,16]$ or estimated by dosimetry [17]. Usually, 30-100 mCi (1.1-3.7 GBq) were administered for remnant ablation in low-risk patients, $100-200 \mathrm{mCi}(3.7-7.4 \mathrm{GBq})$ were administered for adjuvant therapy to destroy suspected unconfirmed cancer, and $200 \mathrm{mCi}(7.4 \mathrm{GBq})$ or more were administered for treatment of known residual or metastatic cancer. Because of the concerns of excess radiation exposure to patients and proposed ATA guidelines [12,13], the administered doses to our patients were relatively higher compared with recently treated patients. Serum thyroglobulin, neck ultrasonography, and diagnostic radioiodine whole-body scans were usually performed for surveillance of thyroid cancer. Additional studies were performed as needed based on patient symptoms. Between 2006 and 2014, the National Health Insurance Service (NHIS) of Korea allowed insurance coverage of F-18 fluorodeoxyglucose (FDG) PET/CT for the detection of recurrent thyroid cancer within 5 years following surgery. Thus, FDG PET/CT was performed for cancer surveillance within 5 years after surgery (between 2006 and 2014) or for the thyroid cancer patients with elevated thyroglobulin, regardless of the presence of any clinical evidence of recurrence (all follow-up period). We also evaluated the potential contribution of PET/CT on the early detection of secondary cancers.

\section{Cancer incidence analysis}


The cancer incidence in Korea was calculated based on data obtained from the Korean statistical information Service (https://kosis.kr, last access at Mar-17-2021). As hematologic cancers were not applied during the washout period, the cancer incidence for hematologic cancers was obtained from 2000 to 2018. Solid and total cancer incidences were obtained from 2002 to 2018. The incidence rate of secondary cancer was expressed as crude and age-standardized rates (CR and ASR, respectively) per 100,000 person-years. The CR was calculated as the total number of incidence cases divided by 100,000 person-years during the follow-up period. The ASR is a weighted average of the age-specific rates, in which the weights represent the proportion of persons in the corresponding age groups of a standard population, Segi's world standard population [18]. The standard error (SE) of the ASR and $95 \% \mathrm{Cl}$ of the standardized rate ratio (SRR) comparison between our study population and the cancer incidence in Korea were calculated based on a previous publication [19].

\section{Statistical analysis}

The follow-up period was determined as the interval between the date of initial RIT and the date of loss of follow-up, date of development of secondary cancer, or the closing date for follow-up, whichever came first. For patients who developed two secondary cancers, the follow-up periods for each cancer was considered for analysis. The analysis of the latency period included the patients who developed secondary cancers two years after RIT. The latency period was defined as the interval between the date of initial RIT and the date of diagnosis of a secondary cancer. The Chi-square test was performed for categorical variables and a one-way ANOVA was performed for continuous variables. We performed a Cox-proportional hazard regression analysis to evaluate each factor related to the development of secondary cancer including age at diagnosis, age at 1 st radioiodine therapy, sex, ATA risk, TNM stages, and the total cumulative dose of radioiodine. A multivariate analysis was also performed using Cox-proportional hazard regression with the following variables: age at 1st RIT, sex, ATA risk, T stage, M stage, and total cumulative dose. A hazard ratio (HR) with a $95 \%$ confidence interval $(\mathrm{Cl})$ was determined for the model and Kaplan-Meir curves were generated. We analyzed the data using $\mathrm{R}$ version 4.0.4 software (https://www.r-project.org) and $p<0.05$ was considered to be statistically significant.

\section{Results}

\section{Patient characteristics}

A total of 3106 patients were included in our study. The mean age at diagnosis of thyroid cancer was $45.7 \pm 13.3$ years old. Four hundred and thirty-seven (14.1\%) patients were male and 2669 (85.9\%) patients were female. Among them, 2944 patients (94.8\%) had papillary carcinoma, 146 patients $(4.7 \%)$ had follicular carcinoma and 16 patients $(0.5 \%)$ had a mixed type. The patients were initially administered $142.0 \pm 49.4 \mathrm{mCi}$ (range, $30-400 \mathrm{mCi}$ ) RIT; 589 patients received 30-100 mCi, 2477 patients received 101-200 $\mathrm{mCi}$, and 40 patients received over $200 \mathrm{mCi}$. The mean total cumulative dose of radioiodine was $216.1 \pm 187.0 \mathrm{mCi}$ (range, 302520): 498 patients received $30-100 \mathrm{mCi}, 1815$ patients received $101-200 \mathrm{mCi}$, and 793 patients received over $200 \mathrm{mCi}$. The mean number of RITs was $1.6 \pm 1.0$ (range, 1-10): 2067 patients underwent RIT once, 651 patients twice, and 388 patients three times or more.

According to ATA risk stratification, 905 (29.1\%) patients were considered low risk, 1661 (53.5\%) were intermediate risk, 476 (15.3\%) were high risk, and $64(2.1 \%)$ could not be assessed for risk. Regarding the AJCC 8th stage, 2498 (80.4\%) patients were stage I, 411 (13.2\%) were stage II, 93 patients (3.0\%) were stage III, 45 patients (1.4\%) were stage IV, and $59(1.9 \%)$ were not evaluable. In addition, 1345 patients (43.3\%) were T1, 641 (20.6\%) were T2, 531 (17.1\%) were T3, 214 (6.9\%) were T4, and 375 (12.1\%) were Tx, 1117 (36.0\%) were N0, 1553 (50.0\%) were N1, and 436 (14.0\%) were Nx, whereas most Nx patients did not have evidence of lymph node involvement by physical examination and ultrasonography assessment. Finally, 2964 (95.5\%) patients were M0, 77 (2.5\%) were M1, and 62 (2.0\%) were Mx (Table 1 and Supplementary Table 1). 
Table 1

Patient characteristics

\begin{tabular}{|c|c|c|c|c|c|c|}
\hline & & $\begin{array}{l}\text { Total } \\
(n=3106)\end{array}$ & $\begin{array}{l}30-100 \mathrm{mCi} \\
(n=498)\end{array}$ & $\begin{array}{l}101-200 \mathrm{mCi} \\
(\mathrm{n}=1815)\end{array}$ & $\begin{array}{l}201 \mathrm{mCi} \\
(\mathrm{n}=793)\end{array}$ & $p$ value \\
\hline \multicolumn{2}{|c|}{ Age at diagnosis (yr) } & $45.7 \pm 13.3$ & $46.2 \pm 12.8$ & $46.2 \pm 12.9$ & $44.4 \pm 14.4$ & 0.0053 \\
\hline \multicolumn{2}{|l|}{ Age at 1st RIT } & $46.0 \pm 13.4$ & $46.3 \pm 12.8$ & $46.4 \pm 13.0$ & $44.8 \pm 14.5$ & 0.0200 \\
\hline \multirow[t]{2}{*}{ Sex } & Male (n) & $437(14.1 \%)$ & $46(9.2 \%)$ & $218(12.0 \%)$ & $173(21.8 \%)$ & $<0.0001$ \\
\hline & Female (n) & $2669(85.9 \%)$ & $452(90.8 \%)$ & $1597(88.0 \%)$ & $620(78.2 \%)$ & \\
\hline \multirow[t]{3}{*}{ Pathology } & PTC & $2944(94.8 \%)$ & $481(96.6 \%)$ & 1709 (94.2\%) & $754(95.1 \%)$ & 0.1562 \\
\hline & FTC & $146(4.7 \%)$ & $15(3.0 \%)$ & $93(5.1 \%)$ & $38(4.8 \%)$ & \\
\hline & Mixed & $16(0.5 \%)$ & $2(0.4 \%)$ & $13(0.7 \%)$ & $1(0.1 \%)$ & \\
\hline \multicolumn{2}{|c|}{ Initial dose of radioiodine } & $142.0 \pm 49.4$ & $56.9 \pm 34.1$ & $154.0 \pm 21.6$ & $168.1 \pm 46.9$ & $<0.0001$ \\
\hline \multicolumn{2}{|l|}{ No. of RIT } & $1.6 \pm 1.0$ & $1.4 \pm 0.6$ & $1.1 \pm 0.5$ & $2.7 \pm 1.2$ & $<0.0001$ \\
\hline \multicolumn{2}{|c|}{ Total cumulative dose (mCi) } & $216.1 \pm 187.0$ & $67.8 \pm 30.7$ & $157.3 \pm 14.8$ & $443.7 \pm 249.6$ & $<0.0001$ \\
\hline \multirow[t]{4}{*}{ ATA risk } & Low & $905(29.1 \%)$ & $204(41.0 \%)$ & $529(29.1 \%)$ & $172(21.7 \%)$ & $<0.0001$ \\
\hline & Intermediate & $1661(53.5 \%)$ & $256(51.4 \%)$ & $997(54.9 \%)$ & $408(51.5 \%)$ & \\
\hline & High & $476(15.3 \%)$ & $37(7.4 \%)$ & $248(13.7 \%)$ & $191(24.1 \%)$ & \\
\hline & N/A & $64(2.1 \%)$ & $1(0.2 \%)$ & $41(2.3 \%)$ & $22(2.8 \%)$ & \\
\hline \multirow[t]{5}{*}{ AJCC 8th stage } & Stage I & 2498 (80.4\%) & 454 (91.2\%) & $1488(82.0 \%)$ & 556 (70.1\%) & $<0.0001$ \\
\hline & Stage II & 411 (13.2\%) & 37 (7.4\%) & $229(12.6 \%)$ & 145 (18.3\%) & \\
\hline & Stage III & $93(3.0 \%)$ & $5(1.0 \%)$ & 57 (3.1\%) & $31(3.9 \%)$ & \\
\hline & Stage IV & 45 (1.4\%) & $1(0.2 \%)$ & $6(0.3 \%)$ & $38(4.8 \%)$ & \\
\hline & $\mathrm{N} / \mathrm{A}$ & 59 (1.9\%) & $1(0.2 \%)$ & 35 (1.9\%) & $23(2.9 \%)$ & \\
\hline \multirow[t]{5}{*}{$\mathrm{T}$} & T1 & $1345(43.3 \%)$ & $309(62.0 \%)$ & $811(44.7 \%)$ & $225(28.4 \%)$ & $<0.0001$ \\
\hline & $\mathrm{T} 2$ & 641 (20.6\%) & $136(27.3 \%)$ & 343 (18.9\%) & $162(20.4 \%)$ & \\
\hline & T3 & $531(17.1 \%)$ & $40(8.0 \%)$ & 337 (18.6\%) & $154(19.4 \%)$ & \\
\hline & $\mathrm{T} 4$ & $214(6.9 \%)$ & $9(1.8 \%)$ & $110(6.1 \%)$ & 95 (12.0\%) & \\
\hline & $\mathrm{N} / \mathrm{A}$ & $375(12.1 \%)$ & $4(0.8 \%)$ & $214(11.8 \%)$ & 157 (19.8\%) & \\
\hline \multirow[t]{3}{*}{$\mathrm{N}$} & No & $1117(36.0 \%)$ & 333 (66.9\%) & $650(35.8 \%)$ & $134(16.9 \%)$ & $<0.0001$ \\
\hline & N1 & 1553 (50.0\%) & $150(30.1 \%)$ & 904 (49.8\%) & 499 (62.9\%) & \\
\hline & $\mathrm{N} / \mathrm{A}$ & $436(14.0 \%)$ & $15(3.0 \%)$ & $261(14.4 \%)$ & $160(20.2 \%)$ & \\
\hline \multirow[t]{3}{*}{ M } & MO & 2967 (95.5\%) & 497 (99.8\%) & 1777 (97.9\%) & $693(87.4 \%)$ & $<0.0001$ \\
\hline & M1 & 77 (2.5\%) & $(0.0 \%)$ & $4(0.2 \%)$ & $73(9.2 \%)$ & \\
\hline & $\mathrm{N} / \mathrm{A}$ & $62(2.0 \%)$ & $1(0.2 \%)$ & $1(0.1 \%)$ & $1(0.1 \%)$ & \\
\hline \multirow[t]{3}{*}{ Second cancer } & Solid & $162(5.2 \%)$ & $19(3.8 \%)$ & $92(5.1 \%)$ & $51(6.4 \%)$ & 0.0718 \\
\hline & Hematologic & $21(0.7 \%)$ & $1(0.2 \%)$ & $13(0.7 \%)$ & $7(0.9 \%)$ & 0.2244 \\
\hline & Total & $183(5.9 \%)$ & $20(4.0 \%)$ & $105(5.8 \%)$ & $58(7.3 \%)$ & 0.0202 \\
\hline
\end{tabular}


The patient follow-up period was $11.9 \pm 4.6$ (range, 1.2-19.6) years. Mean follow-up period from first radioiodine treatment to the development of a secondary cancer was $9.0 \pm 4.1$ (range, 1.2-17.5) years. To compare follow-up periods with the development of second solid and hematologic cancers, the latency period was assessed for secondary cancers that developed two years after the initial RIT. The latency period for hematologic cancers was $7.9 \pm 3.5$ (range, 2.1-14.3) years and that of solid cancers was $9.2 \pm 4.1$ (range, 2.1-17.5) years. There was no significant difference between the latency period and the development of a second solid or hematologic cancer $(p=0.1694)$.

\section{Comparison with Korean cancer incidence}

We assessed 4,874 person-years for males and 32,208 person-years for females in our study. A total of 183 second cancers developed during the follow-up period (162 solid and 21 hematologic cancers) including 32 colon/rectum cancers, 30 breast cancers, 27 stomach cancers, 27 lung cancers, 15 leukemia cases, 8 other/ill-defined cancers, 8 kidney cancers, 6 liver cancers, 6 nonHodgkin's lymphomas, 6 pancreatic cancers, 4 cervical cancers, 3 corpus uteri cancers, 3 ovary cancers, 3 prostate cancers, 2 brain cancers, 1 lip/oral cavity/pharynx cancer, 1 larynx cancer, and 1 bladder cancer. To calculate the Korean cancer incidence, we assessed 846,936,262 person-years for solid and total cancer incidence and 942,327,428 person-years for hematologic cancers. The CRs and ASRs in our study and the ASRs for the Korean population are summarized in Table 2.

Table 2

Comparison of secondary cancer incidence after radioiodine therapy and Korean cancer incidence

\begin{tabular}{|c|c|c|c|c|c|c|c|c|c|c|c|c|}
\hline & \multicolumn{3}{|c|}{ Korean Cancer incidence } & \multicolumn{9}{|c|}{ Our study population } \\
\hline & \multirow[t]{2}{*}{$\begin{array}{l}\text { Solid } \\
\text { cancer }\end{array}$} & \multirow[t]{2}{*}{$\begin{array}{l}\text { Hematologic } \\
\text { cancer }\end{array}$} & \multirow[t]{2}{*}{$\begin{array}{l}\text { Total } \\
\text { cancer }\end{array}$} & \multicolumn{3}{|c|}{ Secondary solid cancer } & \multicolumn{3}{|c|}{$\begin{array}{l}\text { Secondary hematologic } \\
\text { cancer }\end{array}$} & \multicolumn{3}{|c|}{ Secondary cancer (total) } \\
\hline & & & & ASR & SRR & $95 \% \mathrm{Cl}$ & ASR & SRR & $95 \% \mathrm{Cl}$ & ASR & SRR & $95 \% \mathrm{Cl}$ \\
\hline Male & 282.4 & 14.9 & 297.5 & 287.8 & 1.018 & $\begin{array}{l}0.998- \\
1.037\end{array}$ & 30.7 & 2.077 & $\begin{array}{l}1.866- \\
2.288\end{array}$ & 318.1 & 1.069 & $\begin{array}{l}1.049- \\
1.090\end{array}$ \\
\hline Female & 174.0 & 9.9 & 184.0 & 171.3 & 0.985 & $\begin{array}{l}0.958- \\
1.012\end{array}$ & 25.4 & 2.598 & $\begin{array}{l}2.276- \\
2.919\end{array}$ & 196.8 & 1.070 & $\begin{array}{l}1.041- \\
1.099\end{array}$ \\
\hline
\end{tabular}

The CRs for solid cancer incidence in our study were 656.5 in males and 403.6 in females. The ASRs for solid cancer incidence were 287.4 in males and 171.3 in females. ASRs for solid cancer incidence in the Korean population were 282.4 and 174.0 in males and females, respectively. There were no significant differences between our study population and the Korean population for both males (SSR, 1.018; 95\% Cl, 0.998-1.037) and females (SSR, 0.985; 95\% Cl, 0.958-1.012).

The CRs for hematologic cancer incidence in our study was 82.1 in males and 52.8 in females, and ASRs were 30.7 for males and 25.4 for females. ASRs for hematologic cancer incidence in the Korean population were 14.9 and 9.9 for males and females, respectively, and the incidences in our study were significantly higher for both males (SSR, $2.077 ; 95 \% \mathrm{Cl}, 1.866-2.288)$ and females (SSR, 2.598; 95\% Cl, 2.276-2.919) compared with that of the Korean population.

The CRs for the total cancer incidence in our study population were 738.6 and 456.4 for males and females, respectively. The ASRs were 318.1 and 196.8 for males and females, respectively, which were significantly higher than the ASRs for total cancer incidence in the matched Korean population, which were 297.5 (male SSR, 1.069; 95\% Cl, 1.049-1.090) and 184.0 (female SSR, 1.070; $95 \% \mathrm{Cl}$, 1.041-1.099). These data are summarized in Table 2 and Supplementary Table 2.

Factors associated with the development of secondary cancers

A Cox-proportional hazard regression model was used to evaluate the factors associated with the development of secondary cancers (Table 3). Significant prognostic factors were analyzed by univariate analysis including age at diagnosis (HR, 1.059; $95 \% \mathrm{Cl}, 1.047-$ $1.072 ; p<0.001)$, age at 1 st RIT (HR, 1.059; 95\% Cl, 1.046-1.072; $p<0.001)$, male (HR, 1.668; 95\% Cl,1.159-2.402; $p=0.006)$, ATAhigh risk $(\mathrm{HR}, 1.813 ; 95 \% \mathrm{Cl}, 1.187-2.768 ; p=0.006)$, stage II $(\mathrm{HR}, 3.533 ; 95 \% \mathrm{Cl}, 2.553-4.889 ; p<0.001)$, stage III $(\mathrm{HR}, 2.985 ; 95 \% \mathrm{Cl}$, $1.512-5.896 ; p=0.002)$, stage IV (HR, 5.671; $95 \% \mathrm{Cl}, 2.636-12.203 ; p<0.001), \mathrm{T3}-4(\mathrm{HR}, 1.512 ; 95 \% \mathrm{Cl}, 1.099-2.080 ; p<0.001), \mathrm{M} 1$ (HR, 2.171, 95\% Cl, 1.0688-4.414; $p=0.032)$, and total cumulative dose over $200 \mathrm{mCi}(\mathrm{HR}, 1.745 ; 95 \% \mathrm{Cl}, 1.050-2.899 ; p=0.007)$. A 
Kaplan-Meier curve was generated for each factor (Fig. 2). A multivariate analysis identified the independent prognostic factors for the development of secondary cancer including age at 1 st RIT (HR, 1.058; $95 \% \mathrm{Cl}, 1.045-1.071 ; p<0.001)$, male $(\mathrm{HR}, 1.697 ; 95 \% \mathrm{Cl}$, $1.151-2.502 ; p=0.008)$, and total cumulative dose over $200 \mathrm{mCi}(\mathrm{HR}, 1.749 ; 95 \% \mathrm{Cl}, 1.019-3.003 ; p=0.043)$.

Table 3

Cox-proportional hazard regression related to the incidence of secondary cancer

\begin{tabular}{|c|c|c|c|c|c|c|c|}
\hline & & \multicolumn{3}{|c|}{ Univariate analysis } & \multicolumn{3}{|c|}{ Multivariate analysis } \\
\hline & & Hazard Ratio & $95 \% \mathrm{Cl}$ & $p$ value & Hazard Ratio & $95 \% \mathrm{Cl}$ & $p$ value \\
\hline \multicolumn{2}{|c|}{ Age at diagnosis (yr) } & 1.059 & $1.047-1.072$ & $<0.001$ & & & \\
\hline \multicolumn{2}{|c|}{ Age at 1st RIT (yr) } & 1.059 & $1.046-1.072$ & $<0.001$ & 1.058 & $1.045-1.071$ & $<0.001$ \\
\hline Sex & Male & 1.668 & $1.159-2.402$ & 0.006 & 1.697 & $1.151-2.502$ & 0.008 \\
\hline \multirow[t]{3}{*}{ ATA risk } & Low & Ref & & & & & \\
\hline & Intermediate & 1.163 & $0.808-1.674$ & 0.417 & 1.083 & $0.741-1.583$ & 0.682 \\
\hline & High & 1.813 & $1.187-2.768$ & 0.006 & 1.213 & $0.720-2.042$ & 0.468 \\
\hline \multirow[t]{8}{*}{ AJCC stage } & Stage I & Ref & & & & & \\
\hline & Stage II & 3.533 & $2.553-4.889$ & $<0.001$ & & & \\
\hline & Stage III & 2.985 & $1.512-5.896$ & 0.002 & & & \\
\hline & Stage IV & 5.671 & $2.636-12.203$ & $<0.001$ & & & \\
\hline & T1-2 & Ref & & & Ref & & \\
\hline & T3-4 & 1.512 & $1.099-2.080$ & 0.011 & 1.072 & $0.733-1.569$ & 0.719 \\
\hline & N1 & 0.891 & $0.654-1.213$ & 0.463 & & & \\
\hline & M1 & 2.171 & $1.068-4.414$ & 0.032 & 1.104 & $0.446-2.731$ & 0.831 \\
\hline \multicolumn{8}{|c|}{ Total cumulative dose (mCi) } \\
\hline & $30-100$ & Ref & & & & & \\
\hline & $101-200$ & 1.364 & $0.845-2.202$ & 0.203 & 1.288 & $0.789-2.104$ & 0.312 \\
\hline & $201-$ & 1.745 & $1.050-2.899$ & 0.032 & 1.749 & $1.019-3.003$ & 0.043 \\
\hline
\end{tabular}

Role of PET/CT in the detection of second cancer

Among 3106 patients, 1969 patients (63.4\%) underwent PET/CT for surveillance of thyroid cancer and 3482 scans were performed (1.8 \pm 1.5 scans per patients who underwent at least one PET/CT scan). Fifty-one secondary cancers were detected in 1137 patients who did not undergo PET/CT, whereas 132 secondary cancers developed in 1969 patients who underwent PET/CT. In retrospective chart reviews, PET/CT contributed to the detection of secondary cancer in 24 patients, which is $18.2 \%$ of the total 132 cases of secondary cancers in patients who underwent PET/CT. These included 9 lung, 5 colon and rectum, 5 breast, 2 stomach, 1 uterine cervical, and 1 ovarian cancer, as well as 1 non-Hodgkin lymphoma. However, there was no statistical difference in the incidence of secondary cancers between patients who underwent PET/CT or not $(p=0.743)$.

\section{Discussion}

The incidence of secondary solid cancers did not significantly increase in thyroid cancer patients who received RIT compared with that in the Korean population. However, secondary hematologic cancers and total cancer incidences of thyroid cancer patients who underwent RIT were significantly higher compare with that in the Korean population. Patients at older age, male sex, and a total cumulative radiation dose over $200 \mathrm{mCi}$ was associated with a significantly higher incidence of secondary cancer. 
We could not evaluate all patients who underwent total thyroidectomy for thyroid cancer without RIT because most patients underwent RIT after total thyroidectomy for ablation of residual thyroid remnants, according to the conventional guidelines adopted earlier than 2005. Therefore, previous studies included patients who underwent lobectomy as a control, but these studies did not report their cancer status $[9,10,20,21]$. In a large population-based study using NHIS database, they excluded patients with prior cancer development, radiation therapy, or chemotherapy, but they did not include life-span and applied a limited washout period [10, 20]. In this study, we retrospectively reviewed the charts so that we could exclude these factors.

Increased hematologic and solid cancer incidences were observed in a large cohort study of atomic bomb survivors [4, 5]. However, there have not been sufficient studies showing an increased incidence of secondary solid cancers in thyroid cancer patients who underwent RIT, primarily because of a heterogeneous study design and a relatively low incidence of secondary cancer [8]. We observed a slightly increased standardized risk ratio (1.069) of secondary cancer incidence after RIT compared with the total cancer incidence in the Korean population, but no statistical difference between secondary solid cancer incidence after RIT and solid cancer incidence in the Korean population was evident. The CR and ASR for secondary hematologic cancers were significantly increased compared with the hematologic cancer incidence in the Korean population. As many factors affect radiation exposure, it is even more difficult to determine a relationship between radioiodine dose and the development of secondary cancers $[3,11]$.

Silva-Vieira et al. reported an increased incidence of secondary cancer in patients who were administered over 200 mCi of radiation [22], which is consistent with our results. However, Ko et al. reported no significant increase in secondary cancers after RIT in a Taiwanese population-based study [23]. In leukemia, Molenaar et al. reported an increased incidence of secondary hematologic cancers after RIT, especially acute myeloid leukemia and chronic myeloid leukemia [9]. Seo et al. reported that radiation doses exceeding $100 \mathrm{mCi}$ were strongly associated with the development of leukemia in a Korean nationwide population-based study, whereas lower RIT doses were not [10]. Our study also revealed that only one patient developed leukemia in patients who received 30-100 mCi of RIT, whereas leukemia occurred in 20 patients who received over $100 \mathrm{mCi}$. A meta-analysis showed an increased incidence of secondary leukemia after RIT [8]. Although the meta-analysis included over 300,000 patients; an extremely low incidence of leukemia was evident [8].

In this study, the incidence of secondary colorectal cancer, pancreatic cancer, laryngeal cancer, lung cancer, prostate cancer, kidney cancer, leukemia, non-Hodgkin's lymphoma in females, and stomach cancer in females was significantly increased compared with the cancer incidence in the total Korean population (Supplementary Table 2). These results need to be interpreted cautiously. The results can be affected by only one or two cases of each cancer, because of the relatively small number of patients and low incidence. Therefore, we did not perform a subgroup analysis within the dose groups because of a relatively small number and incidences of secondary cancer within each dose group.

Old age, male, and higher total cumulative dose were all associated with an increased risk of secondary cancer in our study population, which is consistent with the Korean cancer registry [1]. M1 stage, a high risk of ATA risk stratification, and a total cumulative radiation dose over $200 \mathrm{mCi}$ were associated with increased risk of secondary cancers in a univariate analysis, however, T, N stage and intermediate risk of ATA were not associated with the increased incidence of secondary cancers. These results suggest that only high-doses of radioiodine for the treatment of metastatic disease is related to the increased risk of a secondary cancer. The treatment dose for ablation $(30-100 \mathrm{mCi})$ and adjuvant therapy $(30-150 \mathrm{mCi})$ is relatively lower than that for therapy of metastatic disease (100-200 mCi) [3]. Patients who received more than $200 \mathrm{mCi}$ received more RIT treatments during the follow-up period.

The patients in our study population received a relatively higher dose of radioiodine compared with the patients who were diagnosed recently with thyroid cancer. Because of improved surgical management and understanding of thyroid cancer, patients currently receive about 30-100 $\mathrm{mCi}$ of radioiodine for ablation purpose $[3,12,24,25]$. Smaller remnants results in lower radiation exposure, even though the same dose of radioiodine is administered. Therefore, RIT for ablation purposes could be less of a concern for the development of secondary cancers.

Based on our results, we should consider the risk benefit for patients when they are exposed to over $200 \mathrm{mCi}$ of radioiodine for therapeutic purposes. Adjuvant treatment with radioiodine is decreased for the low and intermediate risk group, whereas most patients received over $200 \mathrm{mCi}$ if they present with distant metastasis. Because patients with distant metastasis show a survival benefit with higher dose RIT [26], concerns regarding secondary cancer is rather minimal. 
The development of secondary cancers in children and young adults is another major concern. Recently, Seo et al. showed an increased risk of secondary cancer in young adult patients ( $<30$ years old) who received over $100 \mathrm{mCi}$ of radioiodine [20]. Our results indicate an increased risk of secondary cancers in older patients. Children and young adult patients ( $<30$ years old) showed a significantly lower incidence of secondary cancers compared with older patients in our study (Supplementary Table 1). Because of the high survival rate in thyroid cancer, longer follow-up periods are needed to confirm the effect of radioiodine in younger patients.

Interestingly, PET/CT contributed to the detection of $14.8 \%$ of secondary cancers in this study, but there was no statistical difference with respect to secondary cancer incidence. In a previous study involving cancer screening, the cancer detection rate of PET/CT in asymptomatic patients was $1.2-1.44 \%$ and most of these cancers were at an early clinical stage $[27,28]$. Although PET/CT contributes to early detection of secondary cancers in this study, the detection rate was not changed.

There are several limitations to our study. A relatively small incidence and study population was not available to sufficiently determine an effect of radioiodine for each cancer type. Also, we only included patients who underwent RIT, thus a direct comparison with a similar population without radioiodine was not feasible. As we detected secondary cancers meticulously through a retrospective chart review, the probability of under-detection of secondary cancers may still occur, although it is likely negligible.

\section{Conclusion}

Older age, male gender, distant metastasis, and a total cumulative radiation dose over $200 \mathrm{mCi}$ are significantly associated with the development of secondary cancers after RIT in thyroid cancer. We need to assess the risk benefit for patients who receive over 200 $\mathrm{mCi}$ of a total cumulative dose.

\section{Declarations}

Funding: This work was supported by the Korean Thyroid Association Clinical Research Award 2019.

Conflicts of interest/Competing interests: All authors have no conflict of interest, financial, or otherwise.

Availability of data and material: Not applicable

Code availability: Not applicable

Authors' contributions: C.M.H, J.L. performed study design, J.L contributed for funding resources. C.M.H, J-Y.S, S.Y.J, S-W.L. performed data analysis. J-Y.S. statistical assistant and review. C.M.H and J.L wrote initial draft, B.I.K., H-C.S., J-K.Y., K.S.W., S-M.K., I.H.C. contributed for data collection and review of the manuscript.

Ethics approval: The Institutional Review board approved this study.

Consent to Participate: Informed consent was waived by Institutional Review Board.

Consent to Publish: Patients signed informed consent was waived by Institutional Review Board.

\section{References}

1. Jung KW, Won YJ, Kong HJ, Lee ES. Cancer Statistics in Korea: Incidence, Mortality, Survival, and Prevalence in 2016. Cancer Res Treat. 2019;51:417-30. doi:10.4143/crt.2019.138.

2. Kilfoy BA, Zheng T, Holford TR, Han X, Ward MH, Sjodin A, et al. International patterns and trends in thyroid cancer incidence, 1973-2002. Cancer Causes Control. 2009;20:525-31. doi:10.1007/s10552-008-9260-4.

3. Hong CM, Ahn BC. Factors Associated with Dose Determination of Radioactive lodine Therapy for Differentiated Thyroid Cancer. Nucl Med Mol Imaging. 2018;52:247-53. doi:10.1007/s13139-018-0522-0.

4. Hsu WL, Preston DL, Soda M, Sugiyama H, Funamoto S, Kodama K, et al. The incidence of leukemia, lymphoma and multiple myeloma among atomic bomb survivors: 1950-2001. Radiat Res. 2013;179:361-82. doi:10.1667/RR2892.1. 
5. Preston DL, Ron E, Tokuoka S, Funamoto S, Nishi N, Soda M, et al. Solid cancer incidence in atomic bomb survivors: 19581998. Radiat Res. 2007;168:1-64. doi:10.1667/RR0763.1.

6. Kitahara CM, Berrington de Gonzalez A, Bouville A, Brill AB, Doody MM, Melo DR, et al. Association of Radioactive lodine Treatment With Cancer Mortality in Patients With Hyperthyroidism. JAMA Intern Med. 2019. doi:10.1001/jamainternmed.2019.0981.

7. Sawka AM, Thabane L, Parlea L, Ibrahim-Zada I, Tsang RW, Brierley JD, et al. Second primary malignancy risk after radioactive iodine treatment for thyroid cancer: a systematic review and meta-analysis. Thyroid. 2009;19:451-7. doi:10.1089/thy.2008.0392.

8. Yu CY, Saeed O, Goldberg AS, Farooq S, Fazelzad R, Goldstein DP, et al. A Systematic Review and Meta-Analysis of Subsequent Malignant Neoplasm Risk After Radioactive lodine Treatment of Thyroid Cancer. Thyroid. 2018;28:1662-73. doi:10.1089/thy.2018.0244.

9. Molenaar RJ, Sidana S, Radivoyevitch T, Advani AS, Gerds AT, Carraway HE, et al. Risk of Hematologic Malignancies After Radioiodine Treatment of Well-Differentiated Thyroid Cancer. J Clin Oncol. 2018;36:1831-9. doi:10.1200/JC0.2017.75.0232.

10. Seo GH, Cho YY, Chung JH, Kim SW. Increased Risk of Leukemia After Radioactive lodine Therapy in Patients with Thyroid Cancer: A Nationwide, Population-Based Study in Korea. Thyroid. 2015;25:927-34. doi:10.1089/thy.2014.0557.

11. Tulchinsky M, Binse I, Campenni A, Dizdarevic S, Giovanella L, Jong I, et al. Radioactive lodine Therapy for Differentiated Thyroid Cancer: Lessons from Confronting Controversial Literature on Risks for Secondary Malignancy. J Nucl Med. 2018;59:723-5. doi:10.2967/jnumed.118.211359.

12. Haugen BR, Alexander EK, Bible KC, Doherty GM, Mandel SJ, Nikiforov YE, et al. 2015 American Thyroid Association Management Guidelines for Adult Patients with Thyroid Nodules and Differentiated Thyroid Cancer: The American Thyroid Association Guidelines Task Force on Thyroid Nodules and Differentiated Thyroid Cancer. Thyroid. 2016;26:1-133. doi:10.1089/thy.2015.0020.

13. Tuttle RM, Leboeuf R, Robbins RJ, Qualey R, Pentlow K, Larson SM, et al. Empiric radioactive iodine dosing regimens frequently exceed maximum tolerated activity levels in elderly patients with thyroid cancer. J Nucl Med. 2006;47:1587-91.

14. Radivoyevitch T, Sachs RK, Gale RP, Molenaar RJ, Brenner DJ, Hill BT, et al. Defining AML and MDS second cancer risk dynamics after diagnoses of first cancers treated or not with radiation. Leukemia. 2016;30:285-94. doi:10.1038/leu.2015.258.

15. Menzel C, Grunwald F, Schomburg A, Palmedo H, Bender H, Spath G, et al. "High-dose" radioiodine therapy in advanced differentiated thyroid carcinoma. J Nucl Med. 1996;37:1496-503.

16. Beierwaltes WH. The treatment of thyroid carcinoma with radioactive iodine. Semin Nucl Med. 1978;8:79-94. doi:10.1016/s0001-2998(78)80009-9.

17. Maxon HR, Thomas SR, Hertzberg VS, Kereiakes JG, Chen IW, Sperling MI, et al. Relation between effective radiation dose and outcome of radioiodine therapy for thyroid cancer. N Engl J Med. 1983;309:937-41. doi:10.1056/NEJM198310203091601.

18. Segi M, Kyokai NT, Igakubu ThD. Cancer mortality for selected sites in 24 countries. 1950.

19. Boyle P, Parkin DM. Cancer registration: principles and methods. Statistical methods for registries. IARC Sci Publ. 1991:12658.

20. Seo GH, Ae Kong K, Kim BS, Seo YK, Moon BS, Yoon HJ, et al. Radioactive lodine Treatment for Children and Young Adults with Thyroid Cancer in South Korea: A Population-Based Study. J Clin Endocrinol Metab. 2021. doi:10.1210/clinem/dgab192.

21. Molenaar RJ, Pleyer C, Radivoyevitch T, Sidana S, Godley A, Advani AS, et al. Risk of developing chronic myeloid neoplasms in well-differentiated thyroid cancer patients treated with radioactive iodine. Leukemia. 2018;32:952-9. doi:10.1038/leu.2017.323.

22. Silva-Vieira M, Carrilho Vaz S, Esteves S, Ferreira TC, Limbert E, Salgado L, et al. Second Primary Cancer in Patients with Differentiated Thyroid Cancer: Does Radioiodine Play a Role? Thyroid. 2017;27:1068-76. doi:10.1089/thy.2016.0655.

Page 10/13 
23. Ko KY, Kao CH, Lin CL, Huang WS, Yen RF. (131)I treatment for thyroid cancer and the risk of developing salivary and lacrimal gland dysfunction and a second primary malignancy: a nationwide population-based cohort study. Eur J Nucl Med Mol Imaging.

2015;42:1172-8. doi:10.1007/s00259-015-3055-0.

24. American Thyroid Association Guidelines Taskforce on Thyroid N, Differentiated Thyroid C, Cooper DS, Doherty GM, Haugen BR, Kloos RT, et al. Revised American Thyroid Association management guidelines for patients with thyroid nodules and differentiated thyroid cancer. Thyroid. 2009;19:1167-214. doi:10.1089/thy.2009.0110.

25. Singer PA, Cooper DS, Daniels GH, Ladenson PW, Greenspan FS, Levy EG, et al. Treatment guidelines for patients with thyroid nodules and well-differentiated thyroid cancer. American Thyroid Association. Arch Intern Med. 1996;156:2165-72.

26. Durante C, Haddy N, Baudin E, Leboulleux S, Hartl D, Travagli JP, et al. Long-term outcome of 444 patients with distant metastases from papillary and follicular thyroid carcinoma: benefits and limits of radioiodine therapy. J Clin Endocrinol Metab. 2006;91:2892-9. doi:10.1210/jc.2005-2838.

27. Chan HP, Liu WS, Liou WS, Hu C, Chiu YL, Peng NJ. Comparison of FDG-PET/CT for Cancer Detection in Populations With Different Risks of Underlying Malignancy. In Vivo. 2020;34:469-78. doi:10.21873/invivo.11797.

28. Tong J, Zou Y, Jiang J, Shi W, Tao R, Ye J, et al. Cancer screening of asymptomatic individuals using 18F-FDG PET/CT in China: a retrospective study. Discov Med. 2016;22:181-8.

\section{Figures}




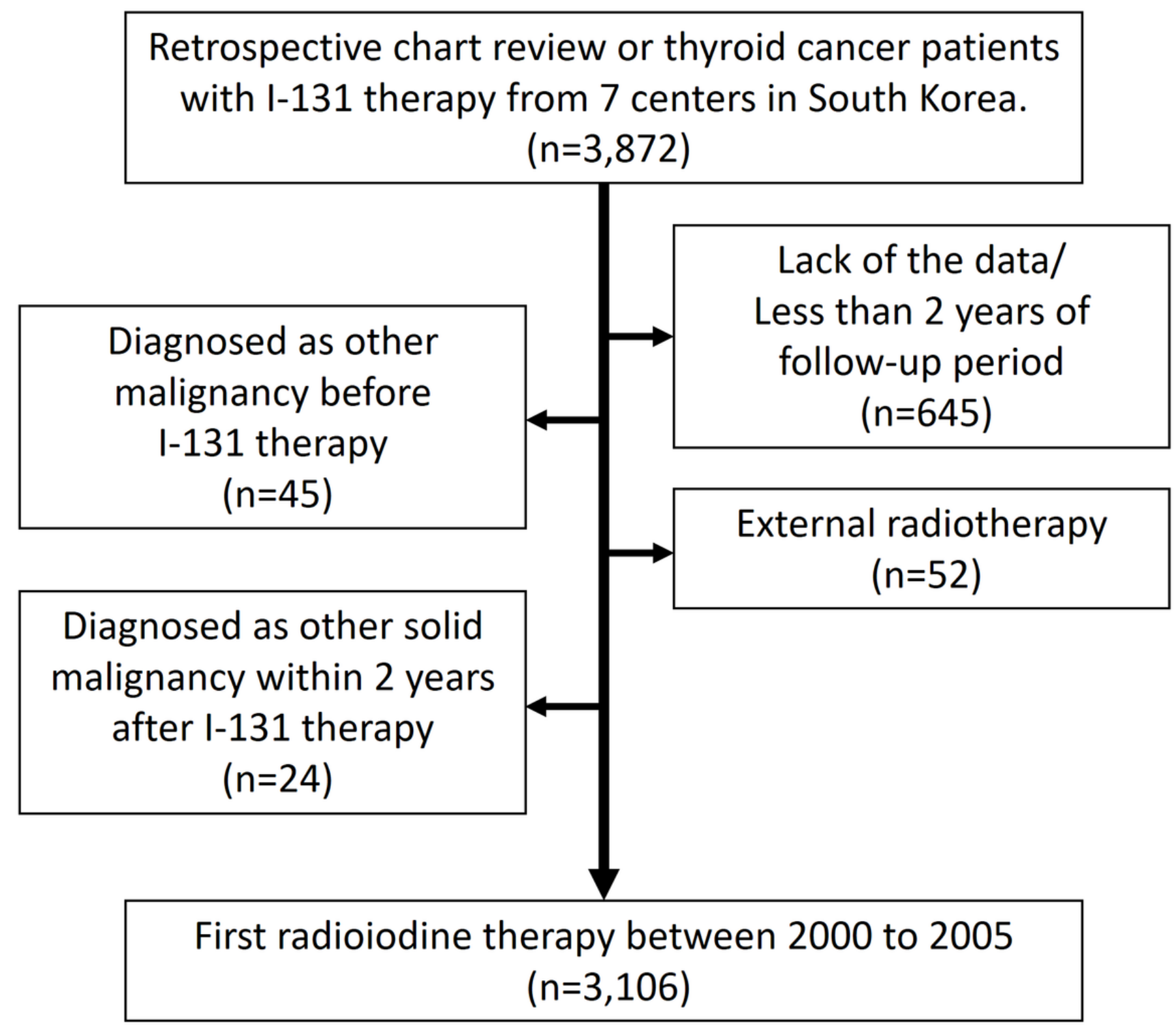

Figure 1

Flow diagram for the inclusion and exclusion criteria of patients 

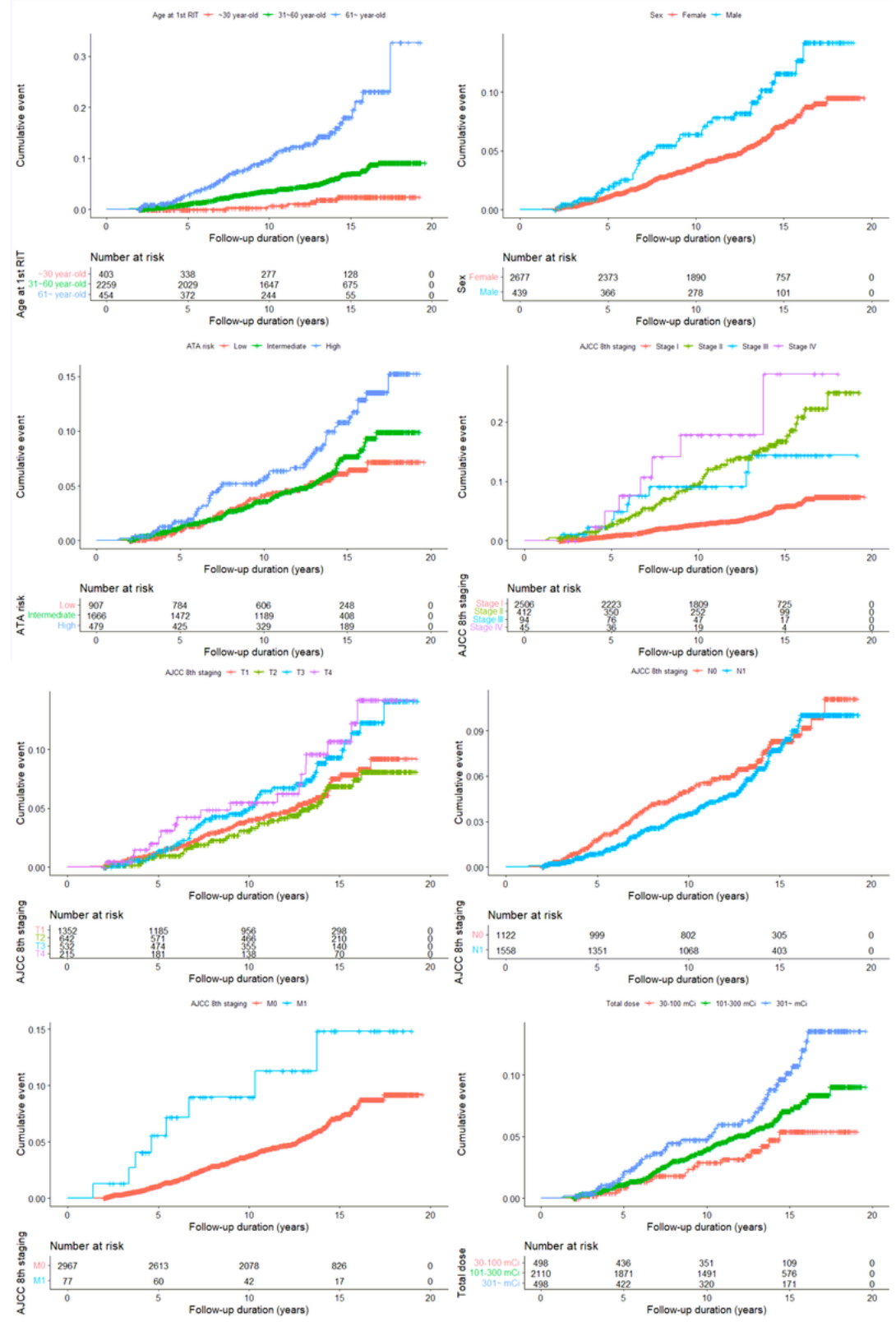

Figure 2

Kaplan-Meier curve for the cumulative incidence of secondary cancers after radioiodine therapy

\section{Supplementary Files}

This is a list of supplementary files associated with this preprint. Click to download.

- SupplementaryTable.docx 